\title{
Iron Excretion Rate
}

National Cancer Institute

\section{Source}

National Cancer Institute. Iron Excretion Rate. NCI Thesaurus. Code C150819.

A determination of the amount of iron being excreted in a biological specimen over a defined period of time. 